\title{
OUTCOME OF POST-PARTUM VAGINAL AND INTRACAESAREAN INSERTION OF IUCD
}

\author{
Hemalatha Kulandai Raj1, Kasthuri Vasu²
}

${ }^{1}$ Associate Professor, Department of Obstetrics and Gynaecology, Government Thoothukudi Medical College, Thoothukudi. ${ }^{2}$ Associate Professor, Department of Obstetrics and Gynaecology, Government Thiruvarur Medical College, Thiruvarur.

\footnotetext{
ABSTRACT

IUCD is a common method of contraception followed in women. The effectiveness and side effects of IUCD is best frequently reported. Here, we have attempted to evaluate the outcome in post-partum vaginal insertion and intracaesarean insertion of copper T.
}

\section{METHODS}

In this study 1098 patients for whom Cu-T inserted in OG Department, Govt. Thoothukudi Medical College, Thoothukudi, were enrolled. Among these patients, 806 underwent vaginal insertion and 292 intracaesarean insertion. Both the groups were compared and analysed. Since there is a significant advantage of intracaesarean insertion over vaginal insertion, all patients who are planned for LSCS should be motivated for intracaesarean insertion of IUCD.

\section{RESULTS}

Both modes of PPIUCD insertion were found to have very low rate of expulsion, vaginal bleeding, infection, missing string and also effective on contraception. Adverse effects are more in vaginal. Hence, intracaesarean from insertion of PPUICD is beneficiary.

\section{CONCLUSION}

PPUICD is an effective approach and may become the best choice as post-partum contraception in both vaginal as well as caesarean delivery.

\section{KEYWORDS}

PPUICD, Vaginal Insertion, Immediate Post-partum, Intracaesarean Insertion.

HOW TO CITE THIS ARTICLE: Raj HK, Vasu K. Outcome of post-partum vaginal and intracaesarean insertion of IUCD. J. Evolution Med. Dent. Sci. 2016;5(63):4488-4490, DOI: 10.14260/jemds/2016/1022

\section{INTRODUCTION}

The increased institutional deliveries are the opportunity to provide women easy access to immediate PPIUCD. This immediate procedure is famous and common in countries like Mexico, China, Egypt and has impact in controlling the population and unmet pregnancy. $(1,2,3)$

The use of an IUCD is simpler, less expensive, immediately reversible method of contraception. Insertion of IUCD after delivery may avoid the discomfort related to internal insertion; however, risk of spontaneous expulsion may be unacceptably high.(1) According to World Health Organisation (WHO) the post-partum period starts after delivery of the placenta and includes the first six weeks after delivery when the woman returns to her Non-Pregnant State.(4) The extended post-partum period is considered up to one year after delivery.(5) Post-partum family planning is the initiation and use of family planning methods during the first year after delivery.

Among women during their first year post-partum in India, 91\% women want to avoid another pregnancy, but only $26 \%$ use family planning methods, $65 \%$ having an unmet need for family planning. Birth to pregnancy interval less than 24 months is associated with the highest risk of

Financial or Other, Competing Interest: None.

Submission 14-07-2016, Peer Review 27-07-2016,

Acceptance 29-07-2016, Published 08-08-2016.

Corresponding Author:

Dr. Hemalatha Kulandai Raj,

Associate Professor,

Department of Obstetrics and Gynaecology,

Government Thoothukudi Medical College,

Thoothukudi.

E-mail: hemasreerithik@gmail.com

DOI: $10.14260 /$ jemds/2016/1022 poor maternal, perinatal, neonatal and infant health outcomes. $(6,7,8)$

- Post placental - within 10 minutes after placenta delivery.

- Immediate post-partum (PPIUCD) - delivery to 48 hours.

- Post-partum - initial six weeks post-delivery.

- Extended post-partum - 6 weeks to one year after delivery. ${ }^{(9)}$

Patients who space 24-30 months have the healthiest infant and child outcomes. There is a common belief that PPIUCD is associated with higher expulsion rate rather than interval IUCD insertion. The objective of this study was to evaluate the efficacy and safety among the two modes of insertion, i.e. post-partum vaginal insertion and intracaesarean insertion.(10,11) Primary complications like failure rate, i.e. accidental pregnancy and secondary complications like expulsion, infection, abdomen pain, bleeding per vagina, white discharge, uterine perforation, psychological disturbances, removal, etc.(10,12)

\section{MATERIALS AND METHODS}

All women admitted for delivery were counselled regarding PPIUCD and enrolled in the study conducted from April 2015 to Sep 2015 in the Department of Obstetrics and Gynaecology at Govt. Thoothukudi Medical College and Hospital, Thoothukudi, Tamilnadu. All eligible women fulfilling the inclusion criteria (post-partum mother of any age and parity within $48 \mathrm{hrs}$. of delivery) were included in the study.

Certain mothers were excluded from the study. They were $>48$ hrs. post-partum, h/o chorionic amnionitis, PROM $>18$ hrs., PIH, HIV not on ART, high risk for chlamydia and 
gonorrhoea, known PID, known pelvic TB, heart disease patients, clients who did not consent for PPIUCD.

The mothers were detailed about the benefits and side effects of IUCD and other available methods of contraception during that period. For all patients who were enrolled in study, an informed consent was taken. In post-partum vaginal insertion, CuT was placed high up in the fundus following vaginal delivery by long Kelley's forceps in lithotomy position, the excess string were cut and mothers were discharged on $48 \mathrm{hrs}$. after delivery.

Those undergoing caesarean section, IUCD were placed high up in the fundus manually holding the IUCD in between the index and the middle finger and passed through the uterine incision the string of CuT pointed to cervical canal. Care is taken not to include string during uterine closure.

All the recipients were examined before discharge and followed up in units scheduled for 6 weeks, 3 months and 6 months. At each unit the subjects were interviewed by staff and physical and pelvic examination were performed by the medical person to verify the presence of IUCD to check for signs of infection and excessive bleeding. Pelvic sonogram and X-ray pelvis were advised to confirm the position and presence of IUCD in patients with missing threads. They were counselled about the irregular bleeding pattern and low back pain for first six weeks. Subjects were advised to return at any time if they experienced pelvic pain/fever/excessive bleeding or unusual vaginal discharge. The primary outcome measure were tabulated as cumulative rate of pregnancy/expulsion/and other mechanically related complications. Followup was done in 6 weeks, 3 months and 6 months.

The information collected, compiled methodically and analysed according to statistician by Chi square test/Fischer exact test on SPS version 15 degrees.

\section{RESULT AND ANALYSIS}

In this study, the acceptance of PPIUCD in both the groups (vaginal and intracaesarean) was best in the age group of 2125 (50.6\% and $47.2 \%$ ) respectively, followed by $26.0 \%$ for vaginal insertion in the age group of (26-30 yrs.), whereas $36.3 \%$ in intracaesarean group comes under the age group of less than 20 years.

\begin{tabular}{|c|c|c|}
\hline $\begin{array}{c}\text { Age Group } \\
\text { (Yrs.) }\end{array}$ & $\begin{array}{c}\text { Vaginal Insertion } \\
(\mathbf{n = 8 0 6})\end{array}$ & $\begin{array}{c}\text { Intracaesarean } \\
\text { Section }(\mathbf{n = 2 9 2})\end{array}$ \\
\hline$<20$ & $139(17.2 \%)$ & $106(36.3 \%)$ \\
\hline $21-25$ & $408(50.6 \%)$ & $138(47.2 \%)$ \\
\hline $26-30$ & $210(26.0 \%)$ & $38(13 \%)$ \\
\hline $31-35$ & $39(4.8 \%)$ & $6(2 \%)$ \\
\hline$>35$ & $10(1.2 \%)$ & $4(1.4 \%)$ \\
\hline \multicolumn{3}{|c|}{ Table 1: Age Distribution } \\
\hline
\end{tabular}

In both the groups, the acceptance of PPIUCD rate was low in the age group of more than 35 yrs. (1.2\% and 1.4\%).

\begin{tabular}{|c|c|c|}
\hline Parity & $\begin{array}{c}\text { Vaginal } \\
\text { Insertion (n=806) }\end{array}$ & $\begin{array}{c}\text { Intracaesarean } \\
\text { Section (n=292) }\end{array}$ \\
\hline 1 & $351(43 \%)$ & $248(84.9 \%)$ \\
\hline 2 & $310(38.4 \%)$ & $39(13.3 \%)$ \\
\hline 3 & $85(10.5 \%)$ & $5(1.7 \%)$ \\
\hline 4 & $11(1.3 \%)$ & $-0(0 \%)$ \\
\hline \multicolumn{2}{|c|}{$\begin{array}{c}\text { Table 2: Parity Distribution Pattern in Vaginal } \\
\text { and Intracaesarean Group in IUCD Insertion }\end{array}$} \\
\hline
\end{tabular}

Primipara mothers accepted PPIUCD more in both the groups than others ( $43 \%$ and $84.9 \%$ ).

\begin{tabular}{|c|c|c|}
\hline $\begin{array}{c}\text { Educational } \\
\text { Status }\end{array}$ & $\begin{array}{c}\text { Vaginal } \\
\text { Insertion } \\
(n=806)\end{array}$ & $\begin{array}{c}\text { Intracaesarean } \\
\text { Section } \\
(\mathrm{n}=\mathbf{2 9 2})\end{array}$ \\
\hline $\begin{array}{l}\text { No formal } \\
\text { Education }\end{array}$ & $46(5.7 \%)$ & $9(3 \%)$ \\
\hline Primary Education & $405(50.2 \%)$ & $105(35.9 \%)$ \\
\hline $\begin{array}{l}\text { Secondary } \\
\text { Education }\end{array}$ & $202(25 \%)$ & $120(41 \%)$ \\
\hline Higher Education & $85(10.5 \%)$ & $58(19.8 \%)$ \\
\hline \multicolumn{3}{|c|}{$\begin{array}{l}\text { Table 3: Educational Status Distribution Pattern in } \\
\text { Vaginal and Intracaesarean Group in IUCD Insertion }\end{array}$} \\
\hline
\end{tabular}

On analysing the educational status, women with primary education accepted vaginal PPIUCD more (56.2\%) than the intracaesarean group (35.9\%). On the contrary, mother with secondary education in intracaesarean group accepted PPIUCD (41\%) than vaginal group (25\%). In both the groups, the mothers with higher education with the acceptance rate being (10.5\% and 19.8\%). Mothers with no education, the acceptance was poor in both the groups ( $5.7 \%$ and $3 \%)$.

\begin{tabular}{|c|c|c|}
\hline Residence & Vaginal Insertion & Intracaesarean Group \\
\hline Rural & $278(34.5 \%)$ & $118(40.4 \%)$ \\
\hline Urban & $510(63.2 \%)$ & $168(57.5 \%)$ \\
\hline Nomadic & $16(1.9 \%)$ & $4(2.92 \%)$ \\
\hline \multicolumn{2}{|c|}{ Table 4: Demographic Distribution of Both the Groups } \\
\hline
\end{tabular}

Urban women were more motivated than rural women in both the groups (63.2\% and 57.2\%) when compared to rural mothers in both the groups (34.5\% and $40.4 \%)$. In both the groups, we had nomadic mothers with acceptance rate of $(1.9 \%$ and $2.9 \%)$ in vaginal and intracaesarean groups respectively.

\begin{tabular}{|c|c|c|}
\hline Side Effects & Vaginal & Intracaesarean \\
\hline Expulsion & $24(2.9 \%)$ & $3(1 \%)$ \\
\hline Bleeding & $43(5.3 \%)$ & $14(4.8 \%)$ \\
\hline Lower Abd Pain & $86(10.6 \%)$ & $22(7.5 \%)$ \\
\hline Pregnancy & $12(1.4 \%)$ & $3(1 \%)$ \\
\hline White Discharge & $48(5.9 \%)$ & $14(4.8 \%)$ \\
\hline $\begin{array}{l}\text { Psychological } \\
\text { Disturbance }\end{array}$ & $16(1.9 \%)$ & $5(1.7 \%)$ \\
\hline Dyspareunia & $6(0.74 \%)$ & $0(0 \%)$ \\
\hline Dysuria & $14(1.5 \%)$ & $0(0 \%)$ \\
\hline Perforation & $0(0 \%)$ & $0(0 \%)$ \\
\hline Missing Strings & $38(4.7 \%)$ & $62(21 \%)$ \\
\hline Low Back Ache & $112(13.8 \%)$ & $48(16.4 \%)$ \\
\hline Spotting PV & $12(1.4 \%)$ & $4(1.4 \%)$ \\
\hline $\begin{array}{r}\text { Table 5: Side } \\
\text { of Vagi }\end{array}$ & $\begin{array}{l}\text { s of PPIUC } \\
\text { d Intracae }\end{array}$ & $\begin{array}{l}\text { Comparison } \\
\text { Group }\end{array}$ \\
\hline
\end{tabular}

Vaginal group had more expulsion rate when compared to intracaesarean group $(2.9 \%$ and $1 \%)$. Both the groups had excessive bleeding $5.3 \%$ and $14.8 \%$ ), which shows that it is a common problem regardless of mode of insertion. Pregnancy was reported in both the groups at the rate of $1.4 \%$ in vaginal and $1 \%$ in the intracaesarean group. In both the groups, mothers had poor sexual drive and psychological disturbance 
in the terms of low mood swing and irritation at the rate of $1.9 \%$ and $1.7 \%$ in vaginal and intracaesarean group. There was no case of perforation in both the groups. Missing strings were documented more in the intracaesarean group (21\%) than vaginal group (4.7\%). In successive follow-ups those with missing strings were subjected for pelvic examination, if needed for USG pelvis for confirmation of presence of IUCD inside the uterus. White discharge was noted in both the groups at the rate of $5.9 \%$ and $14.8 \%$, which was treated. Low backache was more in intracaesarean group (16.4\%) than vaginal group (13.8\%), which was treated with rest and NSAIDs.

\section{DISCUSSION}

As a contraceptive method used during post-partum period, the IUD has a distinct advantage. It is free from systemic side effects and does not affect breast feeding like hormonal methods. It is a reversible method. In addition, IUCD does not require regular user compliance.

The acceptance of PPIUCD was indirectly proportional to the degree of parity similar to most of the studies.(11,12) This may be due to that higher parity subjects opt for permanent methods on contrary to lower parity seeking for spacing methods.

The mode of insertion is important, as it influences the risk of expulsion. In our study, the cumulative expulsion rate after 6 months in vaginal and intracaesarean insertion was almost the same $2.9 \%$ and $3 \%$ respectively in contrast to other studies.(5,6) This is because the expulsion rate is more in post placental insertion than in the post-partum period or interval insertion.

Menorrhagia and spotting were encountered in the same frequency, about $5.3 \%$ in vaginal and $4.8 \%$ in intracaesarean method. This was in concurrence with other studies by Welkovic $S$ et al.(6)

Lower abdominal pain was higher in vaginal $(10.6 \%)$ than in intracaesarean $(7.5 \%)$ group in concordance with Celen $\mathrm{S}$ et al.(1) The prevalence of white discharge was slightly higher $(5.9 \%$ vs $4.8 \%)$ in the vaginal group. Dysuria was present in $1.5 \%$ of patients in the intravaginal group. These findings could be due to ascending infection from the lower genital tract.

Low back pain was less common in the intravaginal segment ( $13.8 \%$ vs $16.4 \%$ ), which may be because of undue bed rest in the postoperative period. Perforation was not encountered in both the groups. Dyspareunia and other psychological disturbances were slightly more in vaginal group.

Similar to the study by Bhutta et al,(7) missing strings was a frequent anxious complaint and observation in the intracaesarean group where the IUCD is placed abnormally high in the fundus, shorter strings in CuT 380A when compared to multiload, curling, retraction of the thread into the cervical canal and uterine cavity or detachment of the thread.

In our study, failure of IUCD in the form of pregnancy with $\mathrm{CuT}$ in situ does not show any preponderance to the mode of IUCD insertion, rather it follows the usual failure rate.

\section{CONCLUSION}

Immediate post-partum insertion of IUCDs appeared safe and effective. Advantages of immediate post-partum insertion include high motivation, assurance that the woman is not pregnant and convenience. However, expulsion rates appear to be higher than with interval insertion. The expulsion rates are almost the same in intravaginal and intracaesarean mode of insertion. But the intracaesarean insertion enjoys less adverse effects like discomfort of insertion, genital tract infections, menorrhagia, spotting, etc. Hence, it is an ideal mode of PPIUCD for spacing pregnancies and improving maternal and child health. All primigravida mothers planned for caesarean delivery should be motivated for intracaesarean IUCD insertion.

\section{REFERENCES}

1. Celen S, Moroy P, Suvak A, et al. Clinical outcomes of early post-placental insertion of intrauterine contraceptive devices. Contraception 2004;69(4):279-82.

2. Eroglu K, Akkuzu G, Vural G, et al. Comparison of efficacy and complications of IUD insertion in immediate postplacental/early post-partum period with interval period: 1 year followup. Contraception 2006;74(5):376-81.

3. Morrison C, Waszak C, Katz K, et al. Clinical outcomes of two early post-partum IUD insertion programs in Africa. Contraception 1996;53(1):17-21.

4. World health organization, Department of reproductive health and research (WHO/RHR) and Johns Hopkins Bloomberg school of public health/center for communication programs (CCP), INFO project. Family planning: a global handbook for providers. Baltimore and Geneva: CCP, WHO 2007.

5. Gupta A, Verma A, Chauhan J. Evaluation of PPIUCD versus interval IUCD (380A) insertion in a teaching hospital of Western UP. Int J Reprod Contracept Obstet Gynecol 2013;2(2):204-8.

6. Welkovic S, Costa LO, Faundes A, et al. Post-partum bleeding \& infection after post-placental IUD insertion. Contraception 2001;63(3):155-8.

7. Bhutta SZ, Butt IJ, Bano K. Insertion of intrauterine contraceptive device at cesarean section. Journal of the College of Physicians and Surgeons Pakistan 2011;21(9):527-30.

8. Kapp N, Curtis KM. Intrauterine device insertion during the post-partum period: a systematic review. Contraception 2009;80(4):327-36.

9. Lara R, Sanchez RA, Aznar R. Application of intrauterine device through the incision of the cesarean section. Ginecol Obstet Mex 1989;57:23-7.

10. Rosales BF, Zamudio AME, Montero CML, et al. Factors for expulsion of intrauterine device TCu380A applied immediately post-partum and after a delayed period. Rev Méd Inst Mex Seguro Soc 2005;43(1):5-10.

11. Grimes DA, Lopez LM, Schulz KF, et al. Immediate postpartum insertion of intrauterine devices. Cochrane Database Syst Rev 2010;(5):CD003036.

12. Gutgutia I, Rani KU, Prateek S, et al. Comparative evaluation of post-partum versus post MTP insertion of intrauterine contraceptive device. Int J Reprod Contracept Obstet Gynecol 2015;4(1):23-9. 